\section{Editor-in-Chief \\ Barbara McLain - (retired Prof.) \\ University of Hawaii, USA}

The Israeli Journal of Aquaculture (IJA) is an interdisciplinary journal that is dedicated to sharing new research and tested applications of aquaculture

The IJA is devoted to scholarly articles for improved aquaculture practices and related industries

The IJA is a peer-reviewed, open-access, electronic journal

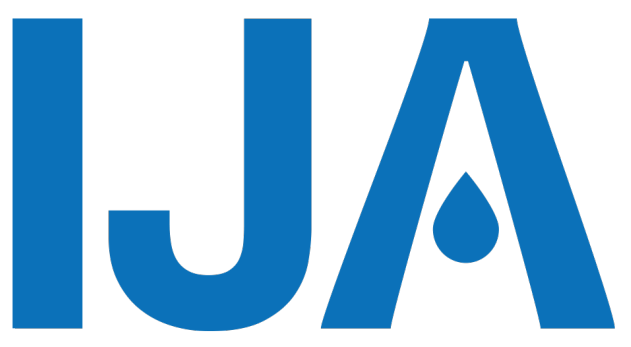

\section{The () Israeli Journal of Aquaculture}

An interdisciplinary online Open Access scientific journal

Published by the

\section{AquacultureHub}

A non-profit organization 501c3

http://www.aquaculturehub.org

in partnership with the

\section{University of Hawaii at Manoa} Library

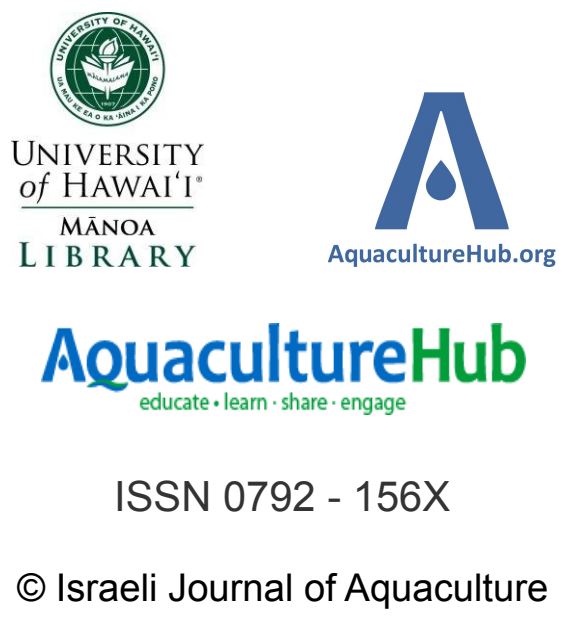




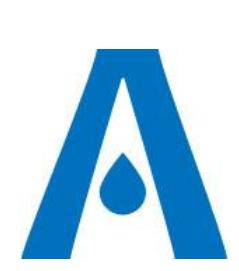

Produced by the AquacultureHub non-profit Foundation the IJA is an open-access, scientific journal, published on http://www.aquaculturehub.org/group/israelijournalofaq uaculturebamidgehija

To read papers free of charge, please register online at the above website.

Sale of IJA papers is strictly forbidden.

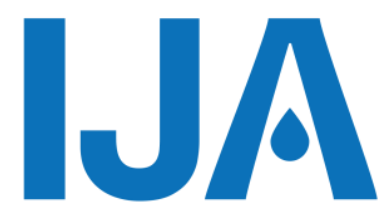

\title{
Effects of Fish Meal Replaced by Maggot Culture on Growth Performance, Body Composition, and Antioxidant Responses of Hybrid Tilapia (Oreochromis niloticus $\times 0$. aureus)
}

\author{
Qiao $\mathbf{Y}^{1,2}$, Mai $\mathrm{K}^{1 *}$, Ai $\mathbf{Q}^{1}$ \\ ${ }^{1}$ Key Laboratory of Aquaculture Nutrition and Feed, Ministry of \\ Agriculture, The Key Laboratory of Mariculture, Ministry of Education, \\ Ocean University of China, Qingdao 266003, China \\ 2 Tongwei Co., Ltd. Chengdu 610000, China
}

Keywords: Oreochromis niloticus $\times 0$. aureus; maggot culture; fish meal replacement; growth performance

\begin{abstract}
This present study was conducted to evaluate the effects of replacing fish meal with maggot culture, on growth performance, body composition, and antioxidant enzyme activity in hybrid tilapia (Oreochromis niloticus $\times 0$. aureus). Five isonitrogenous and isoenergetic diets were formulated to contain graded levels of maggot culture $(0 \%, 1 \%, 2 \%, 4 \%$ and $5 \%)$, which replaced $0 \%$ (the control), 20\%, 40\%, $80 \%$ and $100 \%$ fish meal, respectively. Each diet was randomly fed to triplicate groups of 30 hybrid tilapia (initial mean body weight: $2.12 \pm 0.01 \mathrm{~g}$ ) per tank for 8 weeks. Fish were fed to satiation twice daily (08:00 and 16:00). Results showed that the inclusion of maggot culture did not significantly influence survival, weight gain, feed conversion rate, and morphological parameters of tilapia. Catalase and superoxide dismutase activity were not significantly affected by the supplementation of maggot culture. Also, the inclusion of maggot culture did not significantly influence moisture, protein, lipid, and ash contents of whole body and muscle. Based on these above observations, fish meal could be totally replaced by maggot culture without a negative influence on growth performance, body composition, and antioxidant capability in hybrid tilapia.
\end{abstract}

* Corresponding author. email address e-mail: kmai@ouc.edu.cn. 


\section{Introduction}

Global aquaculture has expanded rapidly in order to meet the increasing demand of humans for aquatic foods. At present, aquafeeds depend heavily on fish meal (FM) as the major protein source due to its high protein quality and balanced amino acid profile (Tacon and Metian, 2008). However, FM is relatively expensive, its availability is declining, and price is dramatically increasing in the world market. Thus, it is imperative to reduce feed cost through exploring less expensive and more sustainable protein sources to substitute FM (Hardy, 2000).

In this regard, insect protein has received wide attention, and some species of insects feed on decaying organic waste such as feces (Zhu et al., 2012). This biological characterization enables these insects to turn organic waste into a valuable biomass rich in protein, which in turn reduces environmental contamination and pathogenic bacteria. Among these insect protein sources, maggot meal is considered to be a good animal source for fish due to its highly nutritive properties with crude protein being between 43.9-62.4\%, and lipid between 12.5-21.0\% (Fasakin et al., 2003). Additionally, it contains several biologically active substances, such as antimicrobial peptides, lectin, and chitin (Zhu et al., 2015). At present, several studies have documented the positive effects of maggot meal on FM replacement in fish species, such as rainbow trout (StHilaire et al., 2007), African catfish (Aneibo et al., 2009), Nile tilapia (Ogunji et al., 2008; Wang et al., 2017), clariid catfish (Fasakin et al., 2003), turbot (Wang et al., 2016), and weather fish (Zhang et al., 2016). Maggot culture is a new type of protein source, which also contains maggot, antibacterial peptides, and symbiotic microorganisms. In general, maggot culture contains $65 \%$ crude protein and balanced amino acids, which may be a better protein source than maggot meal. However, little information is available on the effects of maggot culture on antioxidant capacity in hybrid tilapia

Tilapia is an excellent aquaculture species in tropical and subtropical environments (El-Sayed, 1998) because of its fast growth, good-quality flesh, disease resistance, and adaptability to a wide range of environmental conditions. More than 22 tilapia species are cultured worldwide, and they constitute the third largest group of farmed finfish, after carp and salmonids (El-Sayed, 1999). At present, many studies have been conducted to evaluate the replacement of FM in practical diets for tilapia with cheap, locally available plant and animal protein sources (see review by El-Sayed 1999; Luo et al., 2012). As a continuation of our many studies involved in the utilization of alternative protein sources, the objective of this study was conducted to determine the effects of replacing FM in the diet of hybrid tilapia with maggot culture, on growth and physiological-biochemical indices, which could provide more data for the application of maggot culture in aquafeeds.

Experimental diets.

\section{Materials and Methods}

Five practical diets were formulated to be isonitrogenous and isolipidic. The commercial tilapia diet (the control group) used FM, soybean meal, cottonseed meal, and rapeseed meal as protein sources, and FM was added at the level of $5 \%$. Housefly maggot (Musca domestica) culture was obtained from a local supplier, and their proximate composition is shown in Table 1 . They were added at the levels of $0 \%, 1 \%, 2 \%, 4 \%$ and $5 \%$ to replace $0 \%, 20 \%, 40 \%, 80 \%$ and $100 \%$ of $\mathrm{FM}$, respectively.

The composition and nutrient contents of experimental diets are given in Table 2. Before the formulation of experimental diets, all feed ingredients were analyzed for proximate composition. Then, the dry ingredients were ground and sieved through a $220 \mu \mathrm{m}$ sieve, and thoroughly mixed in a food mixer followed by the addition of soybean oil, which was blended for $5 \mathrm{~min}$ to obtain an emulsion. Distilled water was added to obtain a stiff dough. The moist dough was then extruded through an experimental feed mill (F-26(II), South China University of Technology, China) with a $2.5 \mathrm{~mm}$ die. The resultant noodlelike pellets were dried at air temperature until the moisture was reduced to less than $10 \%$. After drying, the diets were broken up and sieved into adequate pellet sizes $(1.5 \times$ 2.0 and $2.5 \times 3.0 \mathrm{~mm}$ ). All diets were sealed in bags and stored at $-20^{\circ} \mathrm{C}$ until used. 
Table 1. Proximate analysis of the maggot culture (percentage of dry matter, unless stated)

\begin{tabular}{ll}
\hline Items & Analysed value (\%) \\
\hline Moisture & 9.66 \\
Crude protein & 67.04 \\
Ash & 6.76 \\
Crude fibre & 4.47 \\
Calcium & 0.34 \\
Total phosphorus & 0.28 \\
Salinity & 2.56 \\
Lysine & 5.84 \\
Methionine & 1.57 \\
Cystine & 0.73 \\
Threonine & 2.77 \\
Arginine & 4.24 \\
Histidine & 0.67 \\
Phenylalanine & 2.74 \\
Leucine & 4.79 \\
Isoleucine & 2.84 \\
Valine & 4.13 \\
Glutathione (mg/kg) & 40 \\
Lactobacillus (cfu/g) & $4.6 \times 10^{4}$ \\
Bacillus subtilis $(\mathrm{cfu} / \mathrm{g})$ & $5.0 \times 10^{4}$ \\
Bacillus natto (cfu/g) & $1.7 \times 10^{4}$ \\
\hline
\end{tabular}

Table 2. Ingredients and proximate chemical composition of the experimental diet

\begin{tabular}{|c|c|c|c|c|c|}
\hline Ingredients & $D 1$ & $D 2$ & D 3 & D4 & D5 \\
\hline Peru FM & 5 & 4 & 3 & 1 & 0 \\
\hline Maggot culture & 0 & 1 & 2 & 4 & 5 \\
\hline Soybean meal (CP: 43\%) & 20 & 20 & 20 & 20 & 20 \\
\hline Cottonseed meal (CP: 40\%) & 25 & 25 & 25 & 25 & 25 \\
\hline Canola meal CP: $37 \%$ ) & 20 & 20 & 20 & 20 & 20 \\
\hline Wheat middling & 18 & 18 & 18 & 18 & 18 \\
\hline Rice bran & 7 & 7 & 7 & 7 & 7 \\
\hline Soybean oil & 2 & 2 & 2 & 2 & 2 \\
\hline $\mathrm{Ca}\left(\mathrm{H}_{2} \mathrm{PO}_{4}\right)_{2}$ & 2 & 2 & 2 & 2.2 & 2.3 \\
\hline Premix & 1 & 1 & 1 & 1 & 1 \\
\hline $\mathrm{Y}_{2} \mathrm{O}_{3}$ & 0.04 & - & - & - & - \\
\hline Total & 100 & 100 & 100 & 100.2 & 100.3 \\
\hline \multicolumn{6}{|l|}{ Proximate analysis (\%, DM) } \\
\hline Crude protein & 32.59 & 32.59 & 32.59 & 32.59 & 32.59 \\
\hline Crude lipid & 4.49 & 4.47 & 4.45 & 4.41 & 4.39 \\
\hline Crude fibre & 6.05 & 6.08 & 6.10 & 6.15 & 6.18 \\
\hline Crude ash & 7.62 & 7.53 & 7.44 & 7.45 & 7.46 \\
\hline
\end{tabular}

Notes: Premix was provided by Master Bio-Tech Co. Ltd (Qingdao, Shandong, China).

Experimental procedure.

The feeding experiment was conducted in an indoors flow-through aquarium system at the Zhuhai campus, Sun Yat-sen University, Zhuhai, China. Juvenile tilapia were obtained from a local fish fry dealer and stocked in indoor circular fiberglass tanks for one week in order to acclimatize the fish to experimental conditions. During the period of acclimation, all fish received the control diet (Table 2). After the period of acclimation, 30 uniform-sized fish (initial mean weight: $2.12 \pm 0.01 \mathrm{~g}$, mean \pm S.D.) in good health and condition were stocked in each tank (water volume: $300 \mathrm{~L}$ ). Each diet was randomly assigned to triplicate groups. Fish were fed to satiation twice daily (08:00 and 16:00). The uneaten feed was collected immediately with a siphon, then dried and weighed for analysis of feed intake during the feeding period. Fecal matter was also quickly removed during the experiment. Care was taken to ensure that no uneaten diets remained in the tanks during feeding. Fish were bulk weighed every 2 weeks to monitor growth. Tanks were thoroughly cleaned every 2 weeks when the fish were removed for weighing. Any dead fish were removed and not replaced during the experiment. During the experiment, 
the tanks were continuously aerated to maintain dissolved oxygen level near saturation. Water in each tank was replenished to $100 \%$ twice daily, before feeding. The 8 week experiment was conducted in an ambient temperature and natural photoperiod (about $14 \mathrm{~h}$ light/10h dark). Water quality was monitored every morning twice a week. Water temperature was $28.0 \pm 0.5^{\circ} \mathrm{C}$; pH 7.9-8.3; dissolved oxygen was $>6.0 \mathrm{mg} / \mathrm{L}$ and ammonia nitrogen $<0.005 \mathrm{mg} / \mathrm{L}$.

Sampling and analysis.

At the end of the feeding trial, all fish were counted and weighed to determine survival and weight gain following starvation for $24 \mathrm{~h}$. After obtaining the final total weight of the fish in each aquarium, five fish per tank were randomly selected, and frozen at $-18^{\circ} \mathrm{C}$ for subsequent determination of whole-body composition. Another five individuals from each tank were randomly selected, weighed, and dissected to obtain muscle samples, and condition factor (CF), viscerosomatic index (VSI) and hepatosomatic index (HSI) were calculated. Blood samples were collected from the caudal vena with $1 \mathrm{~mL}$ syringe. The obtained serum was used for the analysis of catalase and superoxide dismutase activities. Crude protein $(\mathrm{N} \times 6.25)$ content was determined by the Kjeldahl method after acid digestion using an auto Kjeldahl System (2300-Autoanalyzer, Sweden), lipid by ether-extraction, moisture by oven drying at $105^{\circ} \mathrm{C}$ for $24 \mathrm{~h}$ and ash was determined using a muffle furnace at $550^{\circ} \mathrm{C}$ for $24 \mathrm{~h}$ (AOAC, 1995). SOD was analyzed by Misra and Fridovich (1972) and CAT by Aebi (1984). All enzyme activities are expressed as $U$ (units) per $\mathrm{mg}$ or $\mathrm{g}$ of soluble protein. Soluble protein content of the serum was determined according to the method of Bradford (1976) using bovine serum albumin (BSA) as standard. All these assays were run in triplicate.

Statistical analysis.

The results are presented as means \pm S.D. of three replicate tanks. Data were subjected to one-way analysis of variance (ANOVA). When overall differences were significant $(P<0.05)$, Tukey's test was used to compare the mean values among the treatments. Statistical analysis was performed using the SPSS 12.0 for Windows.

\section{Results}

In the present study, the inclusion of maggot culture did not significantly affect survival, weight gain and FCR (Table 3). Condition factor, hepatosomatic index and viscerosomatic index were not significantly influenced by dietary maggot addition (Table 4). Serum SOD and CAT activities showed no significant differences among five treatments (Table 5). Dietary maggot addition did not significantly influence moisture, crude protein, lipid and ash contents in the whole body and muscle (Table 6 and 7).

Table 3. Effects of maggot culture levels on growth and feed utilization of the hybrid tilapia(Mean \pm S.D., $\mathrm{n}=3$ )

\begin{tabular}{ccccc}
\hline Diet No & $\begin{array}{c}\text { Substitution } \\
\text { levels }(\%)\end{array}$ & $\begin{array}{c}\text { Survival rate } \\
(\%)\end{array}$ & Weight gain (\%) & FCR \\
\hline D1 & 0 & $97.80 \pm 1.91$ & $1107.33 \pm 60.34$ & $1.13 \pm 0.08$ \\
D2 & 20 & $92.23 \pm 6.93$ & $1114.33 \pm 45.65$ & $1.06 \pm 0.05$ \\
D3 & 40 & $96.70 \pm 0.00$ & $1153.67 \pm 54.64$ & $1.05 \pm 0.05$ \\
D4 & 80 & $100.00 \pm 0.00$ & $1055.00 \pm 61.88$ & $1.16 \pm 0.24$ \\
D5 & 100 & $90.00 \pm 6.70$ & $1139.33 \pm 148.84$ & $1.15 \pm 0.09$ \\
\hline
\end{tabular}

Notes: values with the different letters with the same column are significantly different at $P<0.05$. Survival $=100 \times$ final fish number $/$ initial fish number; weight gain $=100 \times$ (final mean body weight - initial mean body weight) / (initial mean body weight); FCR (feed conversion rate) $=g$ feed intake / ( $g$ final fish weight $-g$ initial fish weight $+g$ dead fish).

Table 4. Effects of maggot culture levels on morphological parameters of the hybrid tilapia (Mean $\pm S . D ., n=3$ )

\begin{tabular}{ccccc}
\hline Diet No & $\begin{array}{c}\text { Substitution } \\
\text { Levels (\%) }\end{array}$ & CF & HSI & VSI \\
\hline D1 & 0 & $1.89 \pm 0.01$ & $1.57 \pm 0.08$ & $9.24 \pm 1.17$ \\
D2 & 20 & $1.90 \pm 0.02$ & $1.98 \pm 0.42$ & $9.62 \pm 0.76$ \\
D3 & 40 & $1.90 \pm 0.02$ & $2.13 \pm 0.32$ & $9.87 \pm 0.49$ \\
D4 & 80 & $1.92 \pm 0.03$ & $1.99 \pm 0.20$ & $10.42 \pm 1.63$ \\
D5 & 100 & $1.91 \pm 0.02$ & $1.98 \pm 0.15$ & $9.55 \pm 0.36$ \\
\hline
\end{tabular}

Notes: Values with the different letters within the same row are significantly different at $P<0.05$. CF (condition factor $)=100 \times$ (live weight, $\mathrm{g}) /($ body length, $\mathrm{cm}) 3 ;$ VSI (viscerosomatic index $)=100 \times($ viscera weight) $/$ (body weight); HSI (hepatosomatic index) $=100 \times$ (liver weight) / (body weight). 
Table 5. Effects of maggot culture levels on antioxidant responses of the hybrid tilapia (Mean \pm S.D., $n=3$ )

\begin{tabular}{cccc} 
Diet No. & $\begin{array}{c}\text { Substitution } \\
\text { levels (\%) }\end{array}$ & SOD (U/mg pro $)$ & CAT(U/mg pro $)$ \\
\hline D1 & 0 & $38.23 \pm 10.56$ & $93.74 \pm 25.97$ \\
D2 & 20 & $35.60 \pm 4.16$ & $79.18 \pm 8.97$ \\
D3 & 40 & $37.09 \pm 9.14$ & $85.70 \pm 26.39$ \\
D4 & 80 & $34.08 \pm 3.73$ & $82.78 \pm 3.51$ \\
D5 & 100 & $32.20 \pm 8.52$ & $79.58 \pm 19.27$ \\
\hline
\end{tabular}

Notes: Values in each column without a common superscript are significantly different $(P<0.05)$.

Table 6. Effects of maggot culture levels on whole body composition of the hybrid tilapia (Mean \pm S.D., $n=3$ )

\begin{tabular}{cccccc} 
Diet No & $\begin{array}{c}\text { Substitution } \\
\text { levels (\%) }\end{array}$ & Moisture & Crude protein & Lipid & Ash \\
\hline D1 & 0 & $75.47 \pm 0.63$ & $63.41 \pm 0.18$ & $19.37 \pm 1.02$ & $13.20 \pm 0.48$ \\
D2 & 20 & $74.73 \pm 0.45$ & $61.94 \pm 1.45$ & $20.57 \pm 0.82$ & $12.84 \pm 0.16$ \\
D3 & 40 & $74.85 \pm 0.96$ & $62.82 \pm 1.01$ & $20.24 \pm 1.03$ & $12.86 \pm 0.07$ \\
D4 & 80 & $76.24 \pm 0.21$ & $63.96 \pm 1.92$ & $19.24 \pm 0.79$ & $13.02 \pm 0.15$ \\
D5 & 100 & $75.42 \pm 0.33$ & $63.35 \pm 0.30$ & $19.52 \pm 0.49$ & $12.83 \pm 0.41$ \\
\hline
\end{tabular}

Notes: Values in each column without a common superscript are significantly different $(P<0.05)$. Moisture was presented as the wet weight (\%), and crude protein, lipid and ash was presented as the dry weight (\%).

Table 7. Effects of maggot culture levels on muscle composition of the hybrid tilapia (Mean \pm S.D. , $n=3$ )

\begin{tabular}{cccccc}
\hline Diet No & $\begin{array}{c}\text { Substitution } \\
\text { levels (\%) }\end{array}$ & Moisture & Crude protein & Lipid & Ash \\
\hline D1 & 0 & $77.96 \pm 0.15$ & $88.24 \pm 1.23$ & $2.86 \pm 0.48$ & $6.07 \pm 0.05$ \\
D2 & 20 & $77.89 \pm 0.10$ & $88.86 \pm 1.01$ & $2.78 \pm 0.73$ & $6.03 \pm 0.05$ \\
D3 & 40 & $78.12 \pm 0.07$ & $88.49 \pm 0.69$ & $3.54 \pm 0.70$ & $6.11 \pm 0.02$ \\
D4 & 80 & $77.77 \pm 0.08$ & $88.39 \pm 0.70$ & $3.28 \pm 0.67$ & $6.06 \pm 0.08$ \\
D5 & 100 & $77.96 \pm 0.28$ & $88.20 \pm 0.23$ & $3.19 \pm 0.41$ & $6.02 \pm 0.10$ \\
\hline
\end{tabular}

Note: Values in each column without a common superscript are significantly different $(P<0.05)$.

\section{Discussion}

In the present study, dietary maggot replacement for FM did not significantly affect the survival, weight gain, and FCR, indicating that maggot culture was nutritionally adequate to sustain good growth performance and feed utilization of juvenile hybrid tilapia. Similar results have been found in various fish species where housefly maggot meal can be an alternative protein source for FM replacement (as shown in the introduction). However, different effects of maggot culture on growth were also found in some fish species. The reduced feed efficiency caused by maggot meal was observed in dark barbel catfish (Dong et al., 2013)., Dietary inclusion of defatted maggot meal in clariid catfish did not significantly influence growth performance and nutrient utilization of fish compared to those of fish fed fish meal-based diets (Fasakin et al. 2003). The different response between the present study and others could be attributed to the differences in amino acid and fatty acid profiles of the tested diets or the adaptability of maggot meal protein to different fish. The elevated growth response observed with increasing levels of maggot culture, could be caused by the high level of crude protein and balanced essential amino acid composition in maggot culture. In addition, the present study indicated that CF, HSI and VSI were not significantly influenced by dietary maggot culture, in agreement with the report by Wen et al. (2013).

Apart from growth performance and feed utilization, it is necessary to further evaluate other parameters, such as antioxidant responses. To protect against oxidative damage, organisms have developed a variety of antioxidant defenses that include specialized antioxidant enzymes. Among these antioxidant enzymes, SOD intervenes in the first transformation by dismuting the superoxide free radicals $\left(\mathrm{O}_{2}^{-}\right.$) into $\mathrm{H}_{2} \mathrm{O}_{2}$, whereas CAT converts it into $\mathrm{H}_{2} \mathrm{O}$ and $\mathrm{O}_{2}$ (Dorval et al., 2003). Therefore, changes of antioxidant capacity should be considered as one important aspect for evaluating the nutritive value of alternative proteins for animal and plant protein sources. In the present study, serum SOD and CAT activities showed no significant differences with the inclusion of maggot culture, indicating that total maggot culture replacement for FM did not induce 
oxidative stress in hybrid tilapia. Similarly, dietary maggot meal replacement for FM did not significantly affect SOD activity in the serum and hepatopancreas of Litopenaeus vannamei (Cao et al. 2012). However, maggot meal replacement for FM increased SOD activities in the liver of Gibel carp but reduced the activities of CAT and SOD in dark Barbel catfish (Dong et al. 2013). Low hepatic SOD activity was found in fish fed diets with $\geq 150 \mathrm{~g} / \mathrm{kg}$ housefly maggot meal supplementation (Lin and Mui (2017). It also found depressed catalase activity in Nile tilapia fed diets with $250-350 \mathrm{~g} / \mathrm{kg}$ housefly maggot meal (Ogunji et al. 2007). This discrepancy may be explained by the difference in the maggot meal in other studies, and the maggot culture in the present study. The absence of oxidative stress from maggot culture may be associated with antibacterial peptides and other unknown physiologically active substances which could improve the antioxidant capacity of hybrid tilapia.

The present study indicated that the addition of dietary maggot meal did not significantly influence moisture, crude protein, lipid, and ash contents in the whole body and muscle. Similarly, dietary maggot meal did not affect the muscle proximate composition (Wang et al. (2017). Dietary maggot meal replacement for FM did not significantly influence moisture, ash, lipid, and crude protein contents of whole body in yellow catfish (Wen et al. (2013). Maggot meal addition to the FM-soybean meal-based diet did not significantly influence crude protein and ash contents in the whole body of gibel carp, but the maggot meal-supplemented fish showed significantly higher content of crude lipid than those in the control group (Dong et al. 2013). However, in dark barbel catfish, maggot meal-supplemented fish showed significantly lowered crude lipid than that of the control group, but there were no significant differences in ash content between treatments (Dong et al., 2013).

In conclusion, the whole replacement of FM by maggot culture did not significantly influence growth performance, feed utilization, body composition, and antioxidant responses of the hybrid tilapia, indicating that maggot meal is a good protein source for hybrid tilapia. This will ultimately reduce dietary FM levels and consequently reduce the cost of hybrid tilapia production.

\section{Acknowledgements}

The authors are grateful for financial support by Guangdong xintai biotechnology Co., Ltd. We also thank Professor Lixia Tian from National Sun Yat-sen University (NSYSU) for kind assistance in aquaculture experiments.

\section{References}

Aebi H., 1984. Catalase in vitro. Methods Enzymol, 105: 121-126.

Aniebo A.O., Erondu E.S., Owen O.J., 2009. Replacement of fish meal with maggot meal in African catfish (Clarias gariepinus) diets. Revista Cientifica Udo Agricola, 9(3):666-671.

Association of Official Analytical Chemists (AOAC), 1995. Official Methods of Analysis, $16^{\text {th }}$ ed. Arlington, VA.

Bradford M., 1976. A rapid sensitive method for the quantitation of microgram quantities of protein utilizing the principle of protein-dye binding. Anal Biochem, 72: 248254.

Cao J.M., Yan J., Huang Y.H., Wang G., Zhang R., Chen X., Wen Y., Zhou T., 2012. Effects of replacement of fish meal with housefly maggot meal on growth performance, antioxidant and non-specific immune indexes of juvenile Litopenaeus vannamei. J Fish China, 36: 529-537.

Dong G.F., Yang Y.O., Song X.M., Yu L., Zhao T.T., Huang G.L., Hu Z.J., Zhang J.L., 2013. Comparative effects of dietary supplementation with maggot meal and soybean meal in gibel carp (Carassius auratus gibelio) and darkbarbel catfish (Pelteobagrus vachelli): growth performance and antioxidant response. Aquacult Nutr, 19: 543-554.

Dorval J., Leblond V.S., Hontela A., 2003. Oxidative stress and loss of cortisol secretion in adrenocortical cells of rainbow trout (Oncorhynchus mykiss) exposed in vitro to endosulfan, an organochloride pesticide. Aquat Toxicol, 63: 229-241. 
El-Sayed A.F., 1998. Total replacement of fish meal with animal protein sources in Nile tilapia, Oreochromis niloticus (L.), feeds. Aquac Res, 29: 275-280.

EI-Sayed A.F.M., 1999. Alternative dietary protein sources for farmed tilapia, Oreochromis spp. Aquaculture, 179: 149-168.

Fasakin E.A., Balogun A.M., Ajayi O.O., 2003. Evaluation of full-fat and defatted maggot meals in the feeding of Clariid catfish Clarias gariepinus fingerlings. Aquac Res, 34: 733-738.

Hardy R.W., 2000. Fish feeds and nutrition-fish, feeds, \& nutrition in the new millenium. Aquaculture Magazine, 26(1):85-89.

Lin Y.H., Mui J.J., 2017. Evaluation of dietary inclusion of housefly maggot (Musca domestica) meal on growth, fillet composition and physiological responses for barramundi, Lates calcarifer. Aquac Res, 48: 2478-2485.

Luo Z., Liu C.X., Wen H., 2012. Effect of dietary fish meal replacement by canola meal on growth performance and hepatic intermediary metabolism of genetically improved farmed tilapia strain of nile tilapia, Oreochromis niloticus, reared in fresh water. $J$ World Aquacult Soc, 43: 670-678.

Misra H.P., Fridovich I., 1972. The role of superoxide anion in the auto oxidation of epinephrine and a simple assay of superoxide dismutase. J Biol Chem, 247: 3170-3175.

Ogunji J.O., Nimptsch J., Wiegand C., Schulz C., 2007. Evaluation of the influence of housefly maggot meal (magmeal) diets on catalase, glutathione S-transferase and glycogen concentration in the liver of Oreochromis niloticus fingerling. Comp Biochem Physiol, 147A: 942-947.

Ogunji J., Toor R., Schulz C., Kloas W., 2008. Growth performance, nutrient utilization of Nile Tilapia Oreochromis niloticus fed housefly maggot meal (magmeal) diets. Turk J Fisher. Aquat. Sci, 8: 141-147.

St-Hilaire S., Sheppard C., Tomberlin J.K., Irving S., Newton L., McGuire M.A., Mosely E.E., Hardy R.W., Sealey W., 2007. Fly Prepupae as a feedstuff for rainbow trout, Oncorhynchus mykiss. J World Aquacult Soc, 38: 59-67.

Tacon A G, Metian M. 2008. Global overview on the use of fish meal and fish oil in industrially compounded aquafeeds: trends and future prospects. Aquaculture, 285: 146158.

Wang L., Li J., Jin J., Zhu F., Roffeis M., Zhang X., 2017. A comprehensive evaluation of replacing fish meal with housefly (Musca domestica) maggot meal in the diet of Nile tilapia (Oreochromis niloticus): growth performance, flesh quality, innate immunity and water environment. Aquacult Nutr, 23: 983-993.

Wang Q., He G., Mai K., Xu W., Zhou H., 2016. Fish meal replacement by mixed plant proteins and maggot meal on growth performance, target of rapamycin signaling and metabolism in juvenile turbot (Scophthalmus maximus L.). Aquacult Nutr, 22: 752-758.

Wen Y., Cao J., Huang Y., Wang G., Mo W., Sun Z., Zhou T., Liu X., 2013. Effects of fish meal replacement by maggot meal on growth performance, body composition and plasma biochemical indexes of juvenile yellow catfish (Pelteobagrus fulvidraco). Chin $\mathrm{J}$ Anim Nutr, 25: 171-181.

Zhang H., Li Y., Gu K., Gao F., 2016. Effect of fish meal replacement with maggot meal on the growth performance of Misgurnus anguillicaudatus. Agricult Biotechol, 5(6): 2427.

Zhu F.X., Wang W.P., Hong C.L., 2012. Rapid production of maggots as feedsupplement and organic fertilizer by the two-stage composting of pig manure. Bioresour Technol, 116:485-491.

Zhu F.X., Yao Y.L., Wang S.J., 2015. Housefly maggot-treated composting as sustainable option for pig manure management. Waste Management, 35:62-67. 